InterAção | 135

\title{
TRANSFUSÃO DE SANGUE: DIGNIDADE E AUTONOMIA DOS RELIGIOSOS TESTEMUNHAS DE JEOVÁ
}

\author{
Vinicius de Paula Rezende ${ }^{1}$
}

\section{Resumo}

Este estudo analisa se a dignidade e a liberdade dos religiosos, denominados testemunhas de Jeová, possuem imbricação com a autonomia dos mesmos, quanto à escolha de tratamento médico. Deste modo, visa-se relatar a conceituação formal de direitos fundamentais, bem como, delimitar suas características essenciais. Ademais, constitui objetivo desta pesquisa a compreensão da recusa à transfusão de sangue por mencionados religiosos, sob a ótica dos juízos integrantes da máxima da razoabilidade, consistentes nos juízos de adequação, de necessidade e de razoabilidade stricto sensu. A metodologia desenvolvida consiste na pesquisa teórica ou bibliográfica, a qual se sustenta por intermédio do levantamento bibliográfico feito para se obter parâmetros objetivos de interpretação razoável. Deste modo, utilizou-se o método dedutivo em razão de se considerar premissas universais (não existe ser humano que possua menos dignidade e liberdade que outro) com o escopo de se alcançar assertivas singulares (o religioso testemunha de Jeová possui dignitas na mesma proporção das demais

1 Estudante do mestrado em Direito Público da Faculdade de Direito Prof. Jacy de Assis da Universidade Federal de Uberlândia. Professor da UNIPAC, Campus Araguari, viniciusprezende@yahoo.com.br 
pessoas de direito). Por derradeiro, conclui-se pela existência de direito de autonomia de transfusão de sangue, desde que respeitados os critérios jus-filosóficos da igualdade, democracia, paz e debilidade.

Palavras-chaves: Direitos fundamentais. Dignidade da pessoa humana. Autonomia do paciente.

\section{Abstract}

This study examines whether the dignity and freedom of religion, known as Jehovah's Witnesses, have overlapping with the same autonomy as to the choice of medical treatment. Thus, the aim is to report the formal concept of fundamental rights, as well as define their essential characteristics. Moreover, objective of this research is to understand the refusal of blood transfusions for religious mentioned, from the perspective of members of the highest judgments of reasonableness, consistent in judgments of appropriateness, necessity and reasonableness in the strict sense. The methodology consists of theoretical research and literature, which is supported through the literature review done to obtain objective parameters of reasonable interpretation. Thus, we used the deductive method due to be considered universal premises (there is no human being with less dignity and freedom than others) with the aim of achieving assertive individuals (the Jehovah's Witness religion has the same proportion of dignitas others of law). For the last, we conclude the existence of a right of autonomy of blood transfusion, provided they comply with jus-philosophical criteria of equality, democracy, peace and weakness. 
InterAção | 137

Keywords: Fundamental Rights. Human dignity. Patient's autonomy.

\section{INTRODUÇÃO}

A problematização desta pesquisa repousa no suposto conflito entre o direito à vida e os valores de dignidade e liberdade de escolha à tratamento médico. Deste modo, a busca pelo entendimento do assunto advém da persecução de duas etapas. A primeira se desenvolve nos itens seguintes, por meio de pesquisa teórica, tendo em vista que se funda na concepção doutrinária e objetiva demonstrar as contribuições da Ciência Jurídica para a discussão sobre o direito à vida, bem como, os valores de dignidade e liberdade humanas. Neste diapasão, procede-se ao resgate ideológico do assunto, com fulcro nas noções constitucionais, sobretudo, difundidas por Luigi Ferrajoli e Juan Cianciardo.

A pesquisa se destina a alcançar uma dedução lógica, não apenas por aclarar ou reproduzir teorias dos direitos inatos à humanidade, visto que a singela dedução não é suficiente para averiguar veracidade dos fatos. Assim, este estudo pretende, por meio de premissas universais (critérios e máximas), alcançar conclusões particulares (legalidade ou ilicitude na recusa de transfusão de sangue). Neste sentido, o trabalho explica o conteúdo das premissas e estas premissas sustentarão o futuro desfecho, considerando-se que os casos particulares são dedutíveis de princípios gerais. Enfim, busca-se demonstrar que um acontecimento especial subordina-se a uma lei geral.

A segunda fase desta pesquisa desenvolver-se-á, tão logo, o Conselho de Ética da Universidade Federal de Uberlândia aprove os questionários que serão propostos aos entrevistados, a fim de se rea- 
lizar pesquisa de campo com os religiosos em questão. Neste futuro momento, a busca de dados na realidade social robustecerá o conteúdo teórico, tendo em vista que comparará os sentimentos e as expectativas dos testemunhas de Jeová quanto à utilização de sangue em transfusões. Logo, nesta etapa a posteriori observar-se-á a ocorrência de fatos jurídicos espontâneos no mundo do ser (mundo fático), sob o regramento do ordenamento jurídico brasileiro.

\section{Teoria geral dos direitos fundamentais na Carta Magna brasileira}

A Constituição Federal brasileira de 1988 possui natureza polifacética, tendo em vista que contempla normas de conteúdo, finalidade e origem substancialmente diversas que visam concretizar valores decorrentes de elementos estruturais. "Essas normas, geralmente agrupadas em títulos, capítulos e seções, em função da conexão do conteúdo específico que as vincula, dão caráter polifacético às constituições [...]." (SILVA, 2000, p. 46.)

Esta pesquisa se preocupa com os elementos limitativos e, sobretudo, com os elementos sócio-ideológicos da Lei Maior de 1988, tendo em vista que neles se encontram os direitos fundamentais e, em especial, os direitos sociais. Os elementos limitativos versam sobre os limites da atuação do Estado, restringindo a atividade do Estado, em razão de definirem direitos e garantias individuais (ex.: art. 5\%). Os elementos sócio-ideológicos revelam o compromisso da ordem constitucional estabelecida com determinados princípios ideológicos do Estado (ex.: arts referentes aos direitos sociais da $\mathrm{CF} / 88$, dentre os quais se destaca o direito à saúde). 
InterAção | 139

Portanto, emprega-se a expressão direitos fundamentais, tendo em vista que eles estão presentes no texto constitucional que regula os fundamentos da organização social e política do Estado brasileiro, bem como, porque mencionada locução, além de açambarcar direitos individuais, sociais, de nacionalidade e de cidadania, limita o presente estudo aos direitos protegidos pelo legislador constituinte. Diferenciam-se direitos fundamentais, direitos humanos e direitos naturais, haja vista que os primeiros são direitos dos seres humanos positivados na Constituição Federal, os segundo constituem direitos dos seres humanos assegurados nas normas internacionais, independentemente de previsão na ordem constitucional, que aspiram validade e eficácia universais (direitos supra-positivos) e os terceiros são direitos preexistentes a ordem jurídica (pré-positivos) ${ }^{2}$.

Neste sentido, qualquer direito fundamental somente pode ser compreendido com a substituição do Estado absolutista ante a formação do Estado de Direito (Rechtssat) o qual, enquanto Estado de razão tipicamente burguês, consagra, além do princípio de legalidade do positivismo teórico ou lógico, também o princípio de liber-

2 Deste modo, apresenta-se a formação dos direitos fundamentais, para comprovar sua historicidade. Na Idade Antiga, a filosofia estóica defendeu a unidade humana e a doutrina cristã pregou a igualdade dos homens advindos de um único Deus. Na Idade Média, advogou-se a idéia o valor humano inato em razão da dignidade e, neste caminho evolutivo, floresceu o jusnaturalismo que pugnou pelos direitos naturais. 0 iluminismo conduziu os homens a bradarem armas pelas liberdades públicas e, nos tempos modernos, a positivação dos direitos revelou-se uma conseqüência racional. Os primeiros direitos positivados tinham caráter de estamentais, isto é, somente foram atribuídos a determinadas castas, entretanto, os privilégios se internacionalizaram, por intermédio das declarações universais, e alcançaram a esfera pública gradualmente, universalizando-se. 
dade formal. Nele impera a lei a fim de evitar as arbitrariedades do soberano. Este Estado derruba o monarca do trono e ergue em substituição um altar onde se cultua a legalidade. No lugar do governo dos homens se estabelece o governo das leis. A Administração Pública adquire um limite e tão somente pode agir nos contornos da lei.

Todavia, somente o Estado Democrático institui o princípio do constitucionalismo, por meio do esvaziamento da função liberal da lei, como norma que sistematiza e ajusta o conflito entre autoridade e liberdade. O princípio da constitucionalidade assegura o objetivo de unidade do ordenamento e essa unificação não pode ser feita de maneira hierárquica, mecânica e silogística, sob pena de retorno ao reducionismo meramente legalista. Tal unidade somente revela-se possível tendo-se em conta a própria separação entre os distintos aspectos que compõem os direitos do século XX: a separação entre direitos e lei. $\mathrm{Na}$ tradição francesa o direito legitima o poder legislativo. $\mathrm{Na}$ tradição americana, os direitos possuem primazia em relação à lei, em razão de serem anteriores ao poder legislativo.

A despeito do dissídio doutrinário sobre a paternidade dos direitos fundamentais, disputada entre Declaração de Direito do provo da Virgínia, de 1776, e a Declaração Francesa, de 1789, é a primeira que marca a transição dos direitos de liberdade legais ingleses para os direitos fundamentais constitucionais. As declarações americanas incorporaram virtualmente os direitos e liberdades já reconhecidos pelas suas antecessoras inglesas do século XVII, direitos estes que também tinham sido reconhecidos aos súditos das colônias americanas, com a nota distintiva de que, a despeito da virtual identidade de conteúdo, guardaram as características da universalidade e supremacia dos direitos naturais, sendo-lhes reconhecida eficácia 
InterAção | 141

inclusive em relação à representação popular, vinculando, assim, todos os poderes públicos (SARLET, 2010, p. 43)

Nas sociedades pluralistas atuais a Constituição estabelece o projeto de vida das pessoas. Ele assinala que, na feição atual, a tarefa política primordial não se resume a estabelecer um projeto predeterminado, mas, ao contrário, cumpre ao governo tornar efetivas as condições de vida em comum numa sociedade pluralista e multicultural. A Constituição revela-se como plataforma de partida, o que garante legitimidade para atuação dos setores sociais. Deste modo, é possível afirmar a existência de uma soberania da Constituição em substituição à soberania do Estado. A Lei Maior de 1988 prescreve um compromisso com as possibilidades e representa um centro para o qual tudo se converge. A Constituição consiste numa carta de ponderação, na qual coexistem direitos pluralistas. Portanto, a plenitude da vida exige moderação e na Carta Magna brasileira convivem diversos princípios, não se podendo aceitar normas absolutas.

Neste contexto, cumpre recordar que na órbita constitucional convivem direitos decorrentes do pensamente liberal de cunho individualista3, que surgiram para demarcarem a zona de intervenção do

3 Estes direitos podem ser elencados como direitos de resistência, correspondentes a expressão alemã abwehrrecht ou direitos de defesa ou direitos de status negativo, advindos da formação do Estado de Direito. As normas sobre estes direitos, pela perspectiva do Estado, representam uma competência negativa visto que limitam a atuação do Poder Público em razão da dimensão defensiva da dignidade da pessoa humana. Estes direitos proíbem a interferência do Estado nas decisões das pessoas e asseguram a resistência das pessoas face às condutas estatais, sendo que a ingerência do Estado permite uma repulsa da pessoa natural ou jurídica, dotada do direito de liberdade. 
142 | InterAção

Estado, exigindo uma abstenção do Poder Público.

Eles "[...] têm por titular o indivíduo, são oponíveis ao Estado, traduzem-se como faculdades ou atributos da pessoa e ostentam uma subjetividade que é seu traço mais característico: enfim, são direitos de resistência ou de oposição perante o Estado." (BONAVIDES, 2007, p. 564)

Os direitos sociais, econômicos e culturais surgiram com o escopo de assegurarem a justiça social, exigindo uma ação afirmativa do Poder Público para obtenção das liberdades materiais concretas. A liberdade perante o Estado e igualdade perante a lei (direitos formais) tornam-se liberdade e igualdade por intermédio do governo e das normas legais. Assim, estes valores asseguram "[...] um direito de participar do bem-estar social.” (LAFER, 1991, p. 127)

Os direitos sociais fizeram nascer a consciência de que tão importante quanto salvaguardar o indivíduo, conforme ocorreria na concepção clássica dos direitos da liberdade, era proteger a instituição, uma realidade social muito mais rica e aberta à participação criativa e à valoração da personalidade que o quadro tradicional da solidão individualista, onde se formara o culto liberal do homem abstrato e insulado, sem a densidade dos valores existenciais, aqueles que unicamente o social proporciona em toda a plenitude. (BONAVIDES, 2007, p. 565)

Os denominados direitos sociais ou direitos a prestação ou direitos de status positivo advém da formação do Estado Social, cuja missão precípua foi obter a igualdade substancial. As normas sobre estes direitos, pela perspectiva do Estado, representam uma competência positiva visto que obrigam a atuação do Poder Público em ra- 
InterAção | 143

zão da dimensão prestacional da dignidade da pessoa humana ${ }^{4}$.

Os direitos de solidariedade protegem os grupos humanos e possuem como titulares pessoas indeterminadas, sendo decorrência de um desgaste dos direitos de oposição. Nesta terceira categoria, destacam-se os direitos políticos ou de status ativo, em razão dos quais o indivíduo pode participar da formação das decisões políticas e pode exigir a publicidade efetiva das deliberações tomadas. Estes direitos constituem os pilares que sustentam o Estado Democrático, consubstanciado na expressão "governo do povo, pelo povo e para o povo". As normas relacionadas a estes direitos permitem que o cidadão influencie a esfera de atuação do Estado.

Neste diapasão, percebe-se que todo o sistema dos direitos fundamentais possui como horizontes os direitos de liberdade e os de justiça. $\mathrm{O}$ direito de liberdade se vincula aos direitos de resistência (direitos de defesa ou direitos negativos) visto que protege a livre vontade das pessoas e os direitos lhe vinculados são ilimitados na relação entre particulares. $\mathrm{O}$ direito de justiça se vincula aos direitos referentes à sobrevivência da humanidade atual e futura. Estes direitos de fraternidade integram a nova ordem globalizada (BONAVIDES, 2007, p. 571).

4 Estes direitos permitem que a pessoa exija do poder público uma atuação com a finalidade de melhorar as condições de existência digna e garantir meios materiais para 0 exercício da liberdade. Estas prestações estatais apresentam-se em duas modalidades, sendo que a primeira ocorre quando 0 Estado oferece bens e serviços às pessoas que não podem adquiri-los no mercado e constitui-se como prestação material (ação fática positiva). A segunda espécie de prestação, consistente na prestação normativa (ação normativa positiva), ocorre quando 0 Estado cria os textos legais e reconstrói normas, por intermédio da interpretação. 
Sem a pretensão de esgotar todas as inferências possíveis da globalização na teoria geral dos direitos fundamentais, cumpre elucidar algumas de suas contribuições importantes para a ciência jurídica, dentre as quais estão a contemporaneidade das conclusões e o entrelaçamento do contexto histórico e realidade da sociedade globalizada. O direito e o Estado já não conseguem trilhar um caminho seguro para a garantia dos direitos fundamentais, que muitas vezes estão relegados a último plano.

Desta forma, destacam-se como esteios da alteração do modo de relacionamento do homem com o mundo dois fenômenos históricos: o desenvolvimento de uma rede de transportes marítimos e terrestres e o definitivo desenvolvimento de centros urbanos comerciais e industriais. A rede de transportes aparece como mecanismo eficiente à transposição de aspectos geográficos tanto no sentido de facilitar a locomoção de pessoas como de intensificar as trocas comerciais ${ }^{5}$.

Por um processo natural, o camponês passou a ser consumidor dos bens produzidos na cidade. Este fato estabeleceu uma "[...] relação de constantes trocas e, por conseqüência, de múltiplas e recíprocas dependências" (COLEHO, 2003, p. 43). A burguesia, então, emerge como classe dominante dos meios de produção capitalista. Buscando sempre maior produção e produtividade, a burguesia valeu-

5 Indubitavelmente, 0 desenvolvimento das cidades materializa uma série de relações comerciais e concede outra perspectiva ao campo, vez que este passa a depender dos instrumentos tecnológicos urbanos para produzir bens excedentes àqueles anteriormente utilizados tão somente para consumo de subsistência. Paulatinamente, o campo transmutou-se para atender às necessidades urbanas, assim como para adequar-se à nova realidade produtiva concentrada em aumentar os fluxos de comércio dos produtos do campo. 
InterAção | 145

-se do desenvolvimento tecnológico (surgimento da energia a vapor, do tear mecânico, da máquina de fiar, etc.) para introduzir a produção massificada de bens. A revolução industrial, coadunada à ideologia liberal legitimadora do discurso da burguesia industrial, encaixou-se perfeitamente na lógica de mercado desejada ${ }^{6}$.

$\mathrm{Na}$ esfera política, as interconexões entre economias mundiais promovem a dispersão do poder político tipicamente estatal em diversos organismos financeiros nacionais e internacionais, que condicionam e interferem na adoção de políticas econômicas internas dos países. Reflete-se a questão política a partir de dois pensamentos: otimistas e céticos radicais. Para os otimistas, o Estado-nação abre espaço para um sistema mundial de trocas econômicas autoreguladas. Já os céticos defendem a existência do Estado-nação como resposta social-democrata à globalização.

A concentração de riquezas em poucos pólos econômicos ensejou a proposição de um regime de governabilidade global, o qual envolve regulamentação de moedas, de movimentação de capitais e do comércio, bem como, preservação ambiental. Com este intento, a globalização da economia mundial pode, sem desvencilhar-se de seus objetivos lucrativos, estar a serviço da proteção dos direitos humanos ${ }^{7}$.

6 Deste modo, "[...] emergiu a ideologia liberal como discurso legitimador da burguesia industrial, a qual assumiu gradativamente o poder nas cidades. Afinal, detendo o poder econômico, pôde pouco a pouco organizar-se politicamente." (COELHO, op. cit, p. 45)

7 Note-se a ocorrência de uma crise do Estado como instituição política e do Estado de Direito como referência jurídico-política. Diante da sociedade globalizada e visando atender às demandas sociais, os Estados devem cumprir duas funções: organizar a economia e garantir a cidadania. Tais papéis exprimem a recomposição do Estado 
Neste diapasão, vislumbra-se uma grande contribuição trazida para a cultura científica ao se destacar que o Estado e os direitos fundamentais devem caminhar sempre juntos, de forma que estes não sejam deixados a cargo somente de organizações não-estatais e, ao contrário, sejam objeto de atuação direta de cada país e da sociedade internacional. Qualquer outro caminho que não seja rumo à proteção dos direitos fundamentais desvirtuaria a condição humana de existência, visto que um cidadão é cidadão em qualquer parte do mundo.

\section{Axiologia do princípio da dignidade da pessoa humana na escolha de tratamento médico}

Neste diapasão, qualquer direito fundamental concebe-se como mecanismo jurídico e histórico, do qual emana um mandamento supremo e limitativo ao poder estatal em razão da preponderância da liberdade individual. Ademais, estes direitos são previstos nos dispositivos constitucionais e dotados de normatividade constitucional, por conseguinte à interpretação que transforma o texto em normas. Desta maneira, os direitos possuem uma fundamentalidade formal por decorrerem de normas qualificadas pela supremacia constitucional e porque suas restrições devem observar os limites formais e materiais do art. 60 da Constituição Federal brasileira.

Ademais, eles são dotados de uma fundamentalidade material quando o alcance e a relevância social dos direitos forem demasiados,

e de seus objetivos, os quais devem estar atrelados à proteção dos direitos fundamentais. 
independente de previsão na Lei Maior, o que acarreta um conceito formalmente aberto dos direitos fundamentais. Logo, é preciso desmistificar a idéia segundo a qual direitos fundamentais consistem somente naqueles protegidos por cláusulas pétreas, bem como, mister entender que definir direito fundamental como preexiste à ordem jurídica não lhes garante proteção nem promoção.

Além desta dimensão subjetiva dos direitos fundamentais, que os concebe como direitos subjetivos de resistência, de prestação ou políticos, também persiste uma dimensão objetiva que os revela como elementos fundamentais da sociedade. Sob esta óptica, os direitos fundamentais constituem valor jurídico previsto na Constituição e fornecem diretrizes para os poderes estatais agirem. Desta forma, as normas que os prescrevem são dotadas de imperatividade e eficácia, sobremodo, porque circundam o valor, o princípio e a regra da dignidade da pessoa humana ${ }^{8}$.

Logo, a idéia de dignidade, como valor intrínseco ao ser humano, remonta ao pensamento filosófico da Idade Clássica e à teoria do cristianismo. A dignitas (dignidade) se vincula-se com o status social e com a qualidade distintiva do homem em relação aos demais animais. Todavia, foi Kant quem esclareceu o fundamento filosófico moderno da dignidade, a qual repousa na capacidade abstrata de auto-

8 A compreensão dos direitos fundamentais se revela complexo, porque 0 legislador infraconstitucional, em inúmeras situações, não atua para efetivar o texto constitucional. Assim, estes direitos possuem imbricação imediata com política e economia, o que enseja uma comprometida interpretação normativa. Por conseguinte à salutar introdução, para tratar-se de direitos fundamentais, ressalta-se a relação destes com o princípio constitucional da dignidade da pessoa humana. 
-determinação do ser humano, sendo que a Declaração Universal da ONU segue esta diretriz. Neste sentido, o homem possui dignidade e as coisas possuem preço. Portanto, o homem, em razão da dignidade, torna-se sujeito do direito e não pode ser concebido como objeto, isto é, a pessoa não pode ser "coisificada" ou se tornar um instrumento".

Uma pessoa é um sujeito cujas ações the podem ser imputadas. A personalidade moral não é, portanto, mais do que a liberdade de um ser racional submetido a leis morais [...] Disto resulta que uma pessoa não está sujeita a outras leis senão àquelas que atribui a si mesma (ou isoladamente ou, ao menos, juntamente com outros). (KANT, 2008, p. 65)

Na perspectiva jurídico-constitucional, a dignidade representa uma cláusula em constante processo de construção e atualização e pode ser compreendida como atributo imprescindível para a condição humana. Assim, a dignidade não precisa ser reconhecida pelo direito, pois revela-se preexistente, embora este reconhecimento acarrete suas proteção e promoção. A dignidade possui uma perspectiva política, em razão de assegurar pluralidade de participação e igualdade de tratamento político, prestado pelo Estado, revelando-se a condição para se exercer a ação humana e não como uma das possíveis condições ${ }^{10}$.

9 É "[...] a permanência da concepção kantiana no sentido de que a dignidade da pessoa humana, esta (pessoa) considerada como fim, e não como meio, repudia toda e qualquer espécie de coisificação e instrumentalização do ser humano. (SARLET, Ingo Wolfgang. Dignidade da pessoa humana e direitos fundamentais. 4. ed. Porto Alegre: Livraria do Advogado, 2006, p. 36. )

10 A dignidade também possui um sentido cultural, revelando-se simultaneamente limite e dever do Estado e da comunidade em geral. Deste modo, a dignidade possui uma dupla dimensão: defensiva e prestacional. Na condição de instrumento de defe- 
InterAção | 149

Portanto, o Estado não cumpre sua função protetiva e de promoção da dignidade, se não respeita a liberdade e a autonomia das pessoas, se não assegura as condições mínimas de existência digna nem presta os direitos fundamentais sociais. Por conseqüência, neste Estado, o homem se torna objeto do direito e a dignidade não se apresenta como norma (princípio e valor) ${ }^{11}$.

Desta maneira, a dignidade, como valor fundante do Estado, torna-se o centro do sistema jurídico dos direitos fundamentais. $\mathrm{O}$ texto constitucional, ao ser interpretado, torna-se norma que impõem o respeito a dignidade e, por conseqüência, aos direitos fundamentais. Logo, a dignidade revela-se norma finalistíca e possui função complementar, em razão de contribuir para a solução de conflitos dentre os diversos critérios possíveis. Porém, a dignidade também revela-se como regra, haja vista que ela prescreve condutas de modo imperativo, no sentido de impedir o tratamento do ser humano como objeto do direito. Por derradeiro, a dignidade pode ser definida como pos-

sa do cidadão (limite do Poder Público) a dignidade não pode ser alienada e impõe restrições a atuação estatal. Na dimensão prestacional (tarefa da sociedade política), a dignidade exige uma atuação estatal que proteja, promova e que oferte a possibilidade para todos exercerem sua dignidade.

11 Neste contexto, salienta-se que a Constituição Federal brasileira de 1988, na geração da defesa dos direitos fundamentais, sobremaneira, os denominados sociais, prescreve, em seu artigo $1^{\circ}$, inciso III, que a dignidade da pessoa humana constitui um princípio fundamental, inovando a história do constitucionalismo nacional. Neste diapasão, o legislador constituinte determinou mandamento, segundo 0 qual existem fundamentos que embasam e informam todo 0 ordenamento jurídico e, sobretudo, que respaldam os direitos fundamentais, sendo a dignidade um destes princípios basilares. Desta maneira, reconhece-se que 0 Estado brasileiro existe em função das pessoas, sendo que sua finalidade precípua consiste em assegurar dignidade aos seres humanos. 
tulado normativo em razão de auxiliar a interpretação de normas de primeiro grau ${ }^{12}$.

Resta claro que a questão discutida vai bastante além do estatuto epistemológico da ciência do direito. A natureza dos conceitos da teoria do direito com relação aos conceitos da dogmática jurídica e da natureza dos conceitos da filosofia política da justiça coloca-se como de imprescindível discussão. Em termos de direitos fundamentais e epistemologia jurídica, este substrato da dignidade da pessoa humana constrói uma definição formal de direitos fundamentais, entendidos estes como direito universais e indisponíveis da pessoa física, do cidadão, do sujeito capaz de trabalhar.

Se trata de una tesis bastante comprometida, no sólo en el plano teórico sino también en el metateórico, ya que aborda la añeja cuestión de la relación entre derecho y lógica y, al mismo tiempo, entre derecho y teoría del derecho. Así lo ha puesto de relieve Mario Jori quien, además, me formula una crítica: esta tesis no comporta un cambio de paradigma de la teoría kelseniana del derecho, sino que es sólo su perfeccionamiento crítico. Estoy parcialmente de acuerdo, con dos precisiones. (FERRAJOLI, 2009, p. 180)

12 Neste sentido, insta ressaltar os pontos de contato da dignidade da pessoa humana com os direitos fundamentais. Primeiro, ela legitima a ordem constitucional, representando início e fim dos direitos fundamentais como valor constitucional supremo. Segundo, ela preenche de conteúdo os direitos fundamentais, sobremodo, por vincular-se a noção de autodeterminação ou autonomia pessoal. Terceiro, ela acarreta uma transcendência dos direitos fundamentais em razão de permitir uma eterna construção do sentido jurídico e de impedir a restrição dos mesmos, sendo elemento e medida destes direitos. Quarto, ela impõem ao Estado a proteção, a promoção e a realização efetiva destes direitos fundamentais, especialmente, dos denominados direitos sociais, cuja natureza revela-se prestacional. 
InterAção | 151

A democracia substancial parte do jusnaturalismo e o constitucionalismo rígido confere um inevitável papel normativo à teoria dos direitos fundamentais. As antinomias e lacunas não podem ser eliminadas mediante simples interpretação sistemática, conforme dois tradicionais critérios de prevalência: $1^{0}$ - das normas sucessivas em relação às precedentes e $2^{\circ}$ - das normas especiais em relação às gerais. $\mathrm{O}$ maior respeito à dignidade situa-se no critério a ser utilizado para solucionar conflitos entre normas constitucionais que prescreve o dever de o Estado garantir a vida e o direito de o paciente escolher seu tratamento médico.

Direito de autonomia de transfusão de sangue conforme critérios jusfilosóficos da igualdade, democracia, paz e debilidade dos testemunhas de Jeová

Desta maneira, mister se concentrar na abordagem sobre a conciliação dos conceitos de integração e diferenciação político-social, premente em alguns Estados crescentemente multiétnicos e com numerosas minorias diferenciadoras (no caso os testemunhas de Jeová), compostas por nacionalidades com reivindicações históricas de autogoverno. Partindo da mutação ocorrida no conceito de Estado-nação, entende-se que a regeneração autêntica da democracia no novo contexto atual só será alcançada a partir de um modelo de cidadania plena.

Nesta proposta faz-se necessário desenhar um conceito de cidadania que permita aos grupos sociais desfavorecidos ou marginalizados e às minorias étnicas, religiosas ou culturais, sua regeneração 
no Estado sem perder em virtude disso seus traços diferenciais próprios. Além disso, é preciso um conceito de cidadania que permita a integração diferenciada de tais minorias não só como indivíduos, mas também como grupos específicos.

Atualmente resulta clarividente o fracasso do conceito hegemônico de cidadania integrada, com sua política sociocultural de integração por homogeneização simples. Deste modo, defende-se que uma teoria adequada de cidadania precisa de um estudo dos processos de integração e de diferenciação sociocultural, que são extraordinariamente complexos. As abordagens unilaterais de integração têm o condão de fixar somente um conceito insatisfatório de cidadania. Deve-se buscar uma teoria acerca do complexo processo de integração-diferenciação sobre a identidade pessoal e grupal.

Diante deste espectro, emerge a teoria da cidadania múltipla como resultado de uma adequada educação multicultural, pressupondo um cubo de cidadania fundada em três variáveis fundamentais: elementos (identidade, virtude, legal/civil, político e social); nível geográfico (mundial, continental/regional, nação/Estado e local); e educação (educação cívica em conhecimentos, atitudes e habilidades).

Assim, dissertando-se acerca da conciliação de pertinência e participação, arrisca-se propor um novo conceito de cidadania complexa, o qual pode ser ilustrado mediante o jogo dialético dos conceitos de pertinência e de participação, que são chamados a entrecruzar-se e complementar-se, mas que também podem produzir um descompasso nos âmbitos social e político caso não sejam adequadamente conjugados. 
InterAção | 153

Sólo una ciudadanía compleja puede resolver satisfactoriamente estas tensiones entre pertenencia y participación. En efecto, la ciudadanía compleja es la que atiende adecuadamente a una triple exigencia: a) iguales derechos fundamentales para todos [...]; b) derechos diferenciales de todos os grupos, mayoría y minorías, que componen la estructura organizativa del Estado [...] y c) condiciones mínimas de igualdad para la dialéctica o diálogo libre y abierto de los grupos socioculturales, lo que conlleva una política multicultural [...]. (CARRACEDO, 2000, p. 28)

No que tange aos direitos fundamentais haver-se-á de prevenir possíveis desajustes e até contradições que podem apresentar-se entre os mesmos. Procedida a esta interface alcança-se o sentido da política de reconhecimento e sua respectiva complementação dada pela política universalista, o que viabiliza a definição de um dos fatores primordiais que definem a dignidade da pessoa humana: cada indivíduo e cada povo possui uma personalidade cultural própria.

Por conseqüência, percebe-se que compete ao hermeneuta buscar o equilíbrio na aplicação das normas, sem olvidar que as regras constituem instrumentos de concretização das ponderações obtidas com os princípios. Nesta perspectiva, o sistema jurídico revela-se aberto, sobretudo, pela eficácia horizontal dos direitos fundamentais sociais, a qual permite a modificação do sistema jurídico em razão da constante contextualização dos direitos fundamentais, não sendo razoável conceber o direito como estruturas submissas ao raciocínio lógico-dedutivo, tendo vista que a ordem jurídica deve ser funcionalizada.

Cumpre salientar que o texto legal constitui objeto da interpretação e que a norma consiste no resultado da interpretação, sendo, portanto, diversas as concepções de norma e de dispositivos legais. 
Deste modo, esclarece-se que o intérprete não se limita a descrever o significado dos dispositivos, tendo em vista que ele contribui para a elaboração da significação do texto legal. Enfim, o aplicador do direito promove a reconstrução do significado do texto e, nestes termos, pode-se afirmar que ele constrói normas. A função do juiz é sempre criadora, sendo que a ordem jurídica necessita da lei e do intérprete, ou seja, as normas não decorrem por si só dos textos legais, dependendo necessariamente da interpretação do juiz.

Por conseguinte, ressalta-se que além das normas de primeiro grau (princípios e regras) existem normas de segundo grau que consistem nos postulados. As primeiras possuem como objeto a interpretação e as secundas possuem como objeto a orientação da interpretação. Neste diapasão, os postulados estabelecem diretrizes metódicas que auxiliam o aplicador do direito e não são concebidos como normas que descrevem comportamentos (como as regras) nem como normas que estabelecem um dever-ser ideal (como os princípios).

Portanto, os princípios, enquanto normas, são dotados de eficácia jurídica. A eficácia interna pode ser direta, quando o princípio atua sem intermediação e exerce função integrativa, ou pode ser indireta, quando o princípio somente é aplicado em razão da interposição de regra ou de sub-princípio e, nesta situação, ele exerce a função de delimitar as regras, a função interpretativa ou a função bloqueadora que afasta elementos incompatíveis com o estado de coisas pretendido ${ }^{13}$.

13 0s postulados se dividem em duas categorias: hermenêuticos ou aplicativos. 0s primeiros se destinam a compreensão geral do direito e dentre eles se destaca 0 postulado da coerência, o qual relaciona as normas de primeiro grau com outras normas de primeiro grau superiores, acarretando uma sistematização do direito em 
InterAção | 155

Os princípios não são descritivos e proporcionam escolhas possíveis, sendo que a estas normas se adere, pois vinculam-se aos valores. Eles possuem uma função integrativa e corretiva das regras. Em resumo, qualquer máquina cumpre uma regra quando programada porque sua aplicação é automática e mecânica. Ao contrário, um princípio somente pode ser aplicado em razão de raciocínios em conformidade com os fatos. (ZAGREBELSKY, 2009, p. 48)

Deste modo, conscientes de que as normas sobre direitos fundamentais são principiológicas, mister compreender quatro critérios, enunciados por Luigi Ferrajoli, que podem ser identificados na definição de quais direitos são fundamentais neste contexto da recusa à transfusão de sangue pelos religiosos testemunhas de Jeová.

O primeiro critério consiste para formação de uma definição do que seja direito fundamental consiste no nexo deste conceito com igualdade. A igualdade de titularidade dos sujeitos dos direitos representa fator determinante. Se as pessoas são titulares das mesmas situações jurídicas, por consequência, são iguais. Portanto, a igualdade jurídica representa a igualdade conforme a lei. Os homens são iguais nos mesmos direitos e deveres, perante a lei na medida em que são titulares das mesmas situações jurídicas de modo universal.

O segundo critério repousa no nexo entre direitos fundamentais e democracia, sobremaneira, na sua dimensão substancial. Este critério deriva da definição formal. Somente as constituições demo-

razão de toda norma se fundamentar em outra superior. Diversamente, os postulados aplicativos se destinam a estruturar a aplicação concreta das normas de primeiro grau, sendo que desta modalidade destacam-se os postulados da razoabilidade e da proporcionalidade. 
156 | InterAção

cráticas asseguram direitos e promovem a separação dos poderes. $\mathrm{Na}$ democracia os direitos fundamentais representam limites e vínculos. A democracia formal se refere a "quem" e "como" decidem, sendo relevante para direitos civis e políticos. A democracia substancial se vincula ao "que" se decide (objeto do que é decidido), relevante para direitos de liberdade e sociais. Os direitos fundamentais, portanto, em razão de sua definição pela democracia, explicam a estrutura do Estado e de um núcleo indisponível de direitos conferidos às pessoas ${ }^{14}$.

O terceiro constitui no nexo com a paz, visto que desta decorre a vida e tem como pressuposto a autodeterminação dos povos. A guerra estabelece uma constante instabilidade. A paz internacional deve ser vista como critério que marca dos direitos fundamentais. $\mathrm{O}$ quarto critério concebe-se como o nexo com a lei do mais débil, em razão do qual está protegido o mais fraco fisicamente num estado hobbesiano em relação ao mais forte fisicamente ou economicamente. A lei do mais débil impede o massacra das minorias. Deste modo, este critério se relaciona com o pluralismo social ${ }^{15}$.

14 A democracia sempre é política e a democracia constitucional que marca os direitos fundamentais, consiste em poder do povo para adotar decisão coletiva limitada, que pode suprimir limitar ou derrogar direitos. A democracia constitucional não pode ser chamada de liberal ou social porque a dimensão não é liberal ou social, mas vinculada as decisões legislativas. Os direitos fundamentais são aqueles que atendem a todo o povo e não somente à maioria do povo. No entanto, não é preciso um consenso de todos com se verá em outro critério. 0 pacto constitucional sobre direitos fundamentais funda-se na autonomia política.

15 Portanto, desmistifica-se a existência de um universalismo cultural porque as culturas possuem no seu interior outras micro-culturas. Ademais, também não existe um principio de igualdade universal, haja vista que a história ensina a diferença natural das pessoas. Não se pode exigir, sob a justificativa de uma absoluta verdade, que pessoas sejam obrigadas a receberem material sanguíneo contra a sua vontade 
InterAção | 157

\section{CONSIDERAÇ̃̃ES FINAIS}

Esta pesquisa valoriza, antes mesmo da concepção religiosa, a obediência cega ao binômio principiológico da razoabilidade e proporcionalidade, que se desmembra nos juízos da adequação, da necessidade e da razoabilidade (proporcionalidade) stricto sensu ${ }^{16}$. Este princípio apresenta-se como o caminho para superar-se as disputas metodológicas dos conflitos jusfundamentais. Desta forma, a sua plena aplicação permite resolver os conflitos entre dever de assegurar a vida e direito de escolher o tratamento médico.

O juízo da adequação ou idoneidade revela-se exigido por uma medida legislativa necessariamente, a qual deve ter uma finalidade adequada para alcançar seu êxito. Indaga-se, então, se incumbe aos juízes analisar a adequação de uma medida ou se a competência é exclusiva do legislador. Ressalta-se que a exigência de adequação vem acompanhada do controle de constitucionalidade lato sensu. Se

própria. A recusa ao tratamento médico com doação de sangue revela-se constitucional conforme estes critérios, haja vista que: 1- funda-se na igualdade dos religiosos testemunhas de Jeová em escolherem como quaisquer outras pessoas a melhor forma de cura; 2- respeita a democracia por valorizar uma concepção religiosa que prefere outras formas de tratamento, como as produzidas pelo uso de medicamentos que estimulam 0 aumento do plasma do sangue do paciente e 3- protege 0 mais frágil, visto que os testemunhas de Jeová não representam a maioria da população brasileira e, em razão desta condição, devem ser respeitados em suas opções por tratamento médico ou pela recusa.

16 "Hay acuerdo en definir la proporcionalidad en sentido amplio como una prescripcin en virtude de la cual toda intervención pública ha de ser: a) idônea; b) indispensable; y finalmente, c) proporcionada." (CIANCIARD0, Juan. El conflictivismo em los derechos fundamentales. Navarra/Pamplona: Ediciones Universidad de Navarra, 2000, p. 288) 
os juízes devem controlar a constitucionalidade, podem e devem também examinar a adequação das leis aos fins constitucionais que se propõem ${ }^{17}$.

Em relação ao julgamento de necessidade, também chamado de juízo de indispensabilidade, busca-se a medida adotada pelo legislador enquanto a menos restritiva das normas jusfundamentais dentre as igualmente eficazes. Neste caso, levantam-se três questões: a) a possibilidade do juízo de necessidade, b) o juízo de eficácia e c) a eleição da medida necessária. A eleição da medida necessária determina a existência de vários meios igualmente adequados e eficazes - e/ou a existência de meios alternativos mais eficazes que o eleito - para o cumprimento do fim constitucional. A recusa à doação de sangue revela-se constitucional por ser a menos restritiva de todas, equacionando o grau de restringibilidade da medida adotada, tendo em vista que existem tratamentos não invasivos que aumentam o plasma sanguíneo ${ }^{18}$.

17 No que concerne à profundidade do juízo de adequação, importa estabelecer se análise judicial de idoneidade deve ser técnico, ou seja, se os juízes devem examinar todos os impactos sociais da medida questionada para julgar se foi alcançada a finalidade que 0 legislador se propunha. A resposta exige ter em conta os mandatos contrapostos para chegar a certo equilíbrio: de um lado, o controle de constitucionalidade como imperativo constitucional, que poderá ser base suficiente para admitir que os juízes realizem juízos técnicos e, de outro, a declaração de inconstitucionalidade como ultima ratio do controle, que concilia a constitucionalidade em todos os casos duvidosos. Assim, a recusa à doação de sangue deve se vista como juízo adequado ante a constitucional permissão para liberdade de tratamento médico e em razão da autodeterminação quanto às opções religiosas.

180 sub-princípio da razoabilidade stricto sensu estabelece que a medida deve guardar uma relação razoável com fins legislativos. Não é possível uma aplicação do 
InterAção | 159

\section{REFERÊNCIAS}

ALEXY, Robert. Direitos fundamentais no Estado constitucional democrático. Tradução de Luis Afonso Heck. RDA, Rio de Janeiro, n. 217, p. 55-79, jul./set. 1999.

BONAVIDES, Paulo. Curso de direito constitucional. 20. ed. São Paulo: Malheiros, 2007.

CARRACEDO, José Rubio; ROSALES, José Maria; MÉNDEZ, Manuel Toscano. Ciudadanía, nacionalismo e derechos humanos. Madri: Trotta, 2000.

CIANCIARDO,Juan.El conflictivismoenlos derechosfundamentales. Navarra/Pamplona: Ediciones Universidad de Navarra, 2000.

COELHO, Edihermes Marques. Direitos humanos, globalização de mercados e o garantismo como referência jurídica necessária. São Paulo: Juarez de Oliveira, 2003.

FERRAJOLI, Luigi. Los fundamentos de los derechos fundamentales. 4. ed. Madri: Trotta, 2009.

princípio da razoabilidade sem valoração para 0 equilíbrio entre vantagens e desvantagens. A imposição de doação de sangue resulta em maiores desvantagens que benefícios, porque 0 sangue jamais foi concebido em qualquer ramo da medicina como remédio que cura e concede vida. Enfim, a transfusão de sangue acarreta um aumento da circulação sanguínea e aumenta os batimentos cardíacos, mas não tem o poder de salvar a pessoa, porque esta quando doente somente é curada com medicação. Ademais, a transfusão nos testemunhas de Jeová eliminam a dignidade, ante suas crenças, não se podendo olvidar que toda ofensa a dignidade mata a humanidade que reside no homem. 
160 | InterAção

KANT, Immanuel. A metafísica dos costumes. Tradução Edson Nini. 2. ed. São Paulo: EDIPRO, 2008

LAFER, Celso. A reconstrução dos direitos humanos. São Paulo: Companhia das Letras, 1991.

SARLET, Ingo Wolfgang. A eficácia dos direitos fundamentais: uma teoria geral dos direitos fundamentais na perspectiva constitucional. 10. Ed. Porto Alegre: Livraria do Advogado, 2010.

Dignidade da pessoa humana e direitos fundamentais na Constituição Federal de 1988. Porto Alegre: Livraria do Advogado, 2006.

(Org.). Dimensões da dignidade. Porto Alegre: Livraria do Advogado, 2009.

SILVA, José Afonso da. Curso de direito constitucional positivo. 18. ed. São Paulo: Malheiros, 2000.

ZAGREBELSKY, Gustavo. El derecho dúctil. Madri: Trotta, 2009. 